\title{
Calcium Aluminosilicate Anti-Diarrheal
}

National Cancer Institute

\section{Source}

National Cancer Institute. Calcium Aluminosilicate Anti-Diarrheal. NCI Thesaurus. Code C78858.

A clay compound consisting of aluminosilicate and calcium ions with potential antidiarrheal activity. Calcium aluminosilicate anti-diarrheal consists of microscopically large flat plates of aluminosilicate separated by calcium ions that may sorb toxic chemotherapeutic drugs and their metabolites and inflammatory proteins such as TNFalpha, which may help minimize chemotherapy-mediated or radiation therapy-mediated damage to the intestinal epithelium and so therapy-related diarrhea. 